\title{
Contribuições da Análise do Comportamento em Odontopediatria
}

Behavior Analysis Contributions to Pediatric Dentistry

Contribuciones del Análisis del Comportamiento en Odontopediatría

Olivia Justen Brandenburg \& Verônica Bender Haydu

Universidade Estadual de Londrina
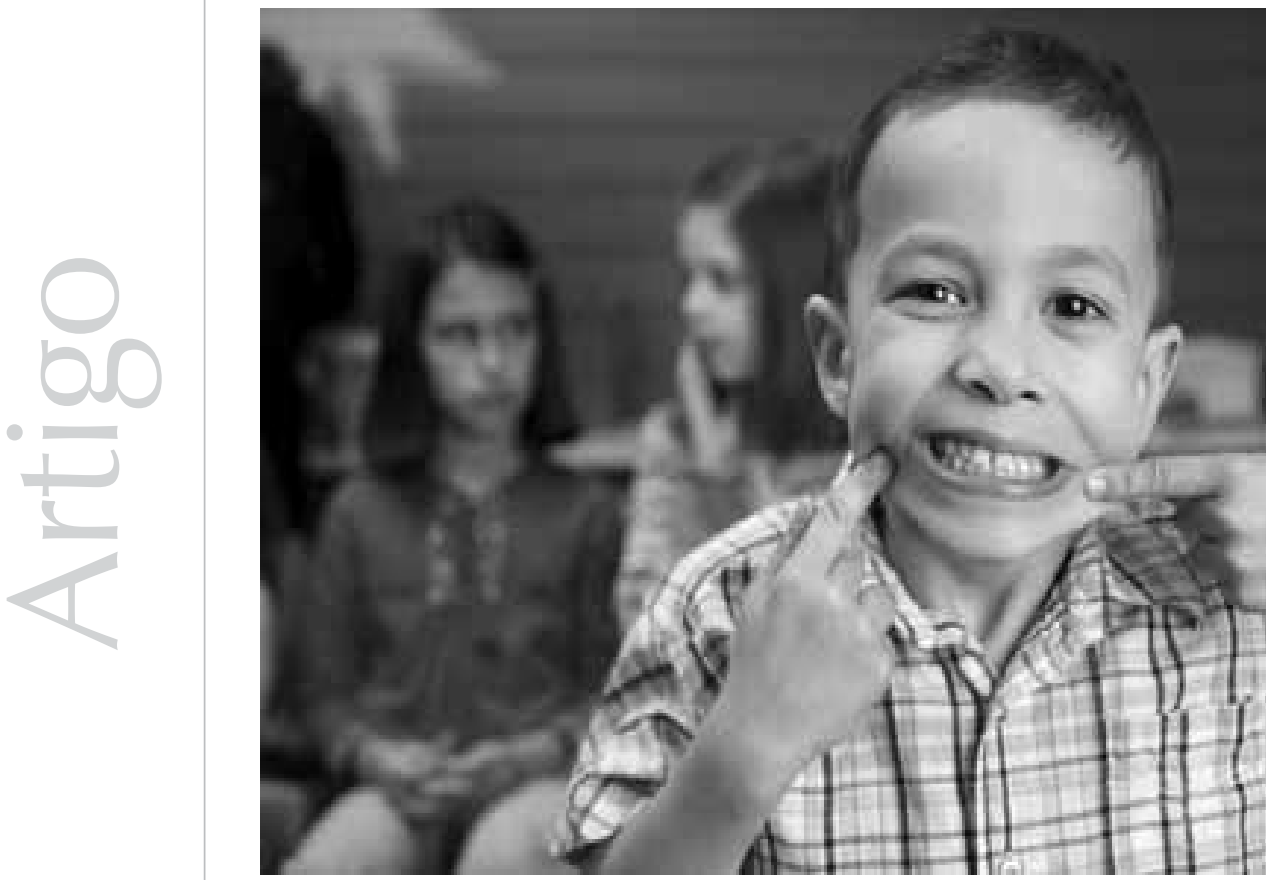
Resumo: Controlar o comportamento de crianças durante o tratamento odontológico é um dos grandes desafios para os dentistas. A falta de cooperação infantil em odontopediatria é um tópico de debate entre pesquisadores, que buscam explicações como medo, ansiedade e experiências aversivas para o fato. Pesquisas de análise do comportamento em contextos de odontopediatria fornecem evidências de que os estímulos aversivos, com função de operações estabelecedoras, alteram o valor de outras contingências presentes no contexto odontológico, como o reforço positivo ou a distração, sendo essa uma possível razão para a dificuldade do manejo de comportamentos não-colaborativos das crianças. Uma breve revisão bibliográfica é apresentada neste trabalho, incluindo a conceituação de operações estabelecedoras, de fuga e de esquiva. Além disso, é feita uma análise da função das operações estabelecedoras no contexto odontopediátrico, sugerindo-se que elas estabelecem condições para a manutenção da não-colaboração de crianças nos consultórios odontológicos. Também são discutidas possibilidades de intervenção com contingências que diminuem as propriedades aversivas da situação.

Palavras-chave: Odontopediatria. Análise do comportamento. Controle aversivo. Crianças.

Abstract: Control children behavior during dentistry treatment is one of the big dentists' challenges. Uncooperative children behavior in pediatric dentistry is a topic of debate among researchers, who look for different explanations like fear, anxiety and aversive experiences for this kind of reaction. Behavior analysis' research in pediatric dentistry contexts provides evidence that the aversive stimulus as a establishing operation changes the value of other contingencies in the dental context, such as positive reinforcement or distraction, and this is a possible reason for the difficulty of managing children disruptive behaviors. A brief literature review is presented in this work, including the concept of establishing operations, avoidance and escape. Moreover, the function of establishing operations in the pediatric dentistry context is analyzed, suggesting that they establish conditions for the maintenance of children disruptive behavior in the dentistry clinics. Possibilities of intervention with contingencies that reduce aversive proprieties of the situation are discussed.

Keywords: Pediatric dentistry. Behavior analysis. Aversive control. Children.

Resumen: Controlar el comportamiento de niños durante el tratamiento odontológico es uno de los grandes desafíos para los dentistas. La falta de cooperación infantil en odontopediatría es un tópico de debate entre investigadores, que buscan explicaciones como miedo, ansiedad y experiencias adversas para el hecho. Pesquisas de análisis del comportamiento en contextos de odontopediatría suministran evidencias de que los estímulos adversos, con función de operaciones establecedoras, alteran el valor de otras contingencias presentes en el contexto odontológico, como el refuerzo positivo o la distracción, siendo ésa una posible razón para la dificultad del manejo de comportamientos de no colaboración de los niños. Una breve revisión bibliográfica es presentada en este trabajo, incluyendo la conceptuación de operaciones establecedoras, de fuga y de esquiva. Además, es hecho un análisis de la función de las operaciones establecedoras en el contexto odontopediatrico, sugiriéndose que ellas establecen condiciones para el mantenimiento de la no colaboración de niños en los consultorios odontológicos. También son discutidas posibilidades de intervención con contingencias que disminuyen las propiedades adversas de la situación.

Palabras clave: Odontopediatría. Análisis del comportamiento. Control adverso. Niños.

Dentistas que atendem crianças, além de serem habilitados no uso dos procedimentos técnicos, devem estar preparados para lidar com o seu comportamento, porque é muito freqüente as crianças não colaborarem para que o tratamento seja realizado. Por essa razão, os dentistas podem se beneficiar dos resultados das pesquisas que vêm sendo conduzidas na área da análise do comportamento, que fornecem evidências que permitem compreender porque as crianças se comportam como o fazem, quando submetidas ao atendimento odontopediátrico. Além disso, esses estudos permitem prever o comportamento e estabelecer estratégias eficazes de intervenção.

A American Academy of Pediatric Dentistry (AAPD, 2005-2006) publica regularmente um guia denominado Guia de Manejo do Comportamento Infantil, que descreve diversas técnicas para intervenção em situações de atendimento odontopediátrico, envolvendo estratégias de distração, de reforço positivo, de restrição física e outras. O objetivo desse manual é "promover um 
Skinner

(1953/1993), no

livro Ciência e

Comportamento

Humano,

reconheceu

que havia

um conjunto

de eventos

antecedentes que não

correspondiam

aos que são

definidos

como estímulo

discriminativo e

como estímulo eliciador, e

dedicou um

capítulo desse

livro à descrição dos efeitos de eventos

ambientais como a privação,

a saciação e os estímulos aversivos. melhor entendimento da necessidade de uma boa saúde dentária e do processo pela qual ela é conseguida" (AAPD, 20052006, p. 92). Acredita-se que a maioria dos odontopediatras é capaz de aplicar essas técnicas, no entanto, é comum não saberem porque elas funcionam em alguns casos e em outros não, ou seja, eles não entendem porque as crianças reagem de forma tão diversificada quando expostas a um mesmo procedimento.

As situações mais difíceis enfrentadas pelos odontopediatras são aquelas em que as crianças, principalmente as mais novas, não colaboram com a realização do tratamento, chorando, gritando, movimentando a cabeça e o corpo, e fazendo tentativas de sair da cadeira. Esses comportamentos de nãocolaboração são, geralmente, atribuídos ao medo, a traumas, a condições fisiológicas ou a outros fatores inerentes ao indivíduo, sendo dado pouco valor para os eventos presentes no ambiente odontológico. Para o analista do comportamento, esses eventos ambientais, que são classificados com base em suas funções comportamentais em estímulos eliciadores, estímulos reforçadores, estímulos punidores, operações estabelecedoras e estímulos discriminativos, são tão relevantes quanto possíveis fatores herdados, e devem ser considerados para se fazer uma análise apropriada do comportamento das crianças.

Tendo como base a análise funcional do comportamento, o presente artigo visa a apresentar uma descrição dos processos de interação que podem ocorrer no ambiente odontopediátrico quando crianças são submetidas a procedimentos de intervenção. Para isso, são analisados, inicialmente, o conceito de operação estabelecedora e a relação deste com o princípio do reforço negativo dentro dos paradigmas dos comportamentos de fuga e esquiva. Em seguida, são feitas análises desses conceitos no contexto da odontopediatria a partir de resultados de pesquisas. Finalmente, são levantadas possibilidades de planejamento de contingências que diminuam as propriedades aversivas do contexto odontológico para crianças não-colaboradoras.

\section{Operações estabelecedoras e comportamentos de fuga e de esquiva}

Skinner (1953/1993), no livro Ciência e Comportamento Humano, reconheceu que havia um conjunto de eventos antecedentes que não correspondiam aos que são definidos como estímulo discriminativo e como estímulo eliciador, e dedicou um capítulo desse livro à descrição dos efeitos de eventos ambientais como a privação, a saciação e os estímulos aversivos. Além dessa relação da privação com o efeito do reforço, Skinner descreveu que um organismo em privação tende a apresentar um aumento na freqüência de todos os comportamentos relacionados ao término dessa condição. Um indivíduo privado de água apresenta comportamentos operantes que, no passado, produziram como conseqüência a água, como, por exemplo, ir até um bebedouro ou comprar uma garrafa de água. Skinner considerou ainda que, assim como um indivíduo em privação repete comportamentos que no passado produziram água ou outro líquido, quando um evento aversivo está presente numa determinada situação, ele emite comportamentos que foram seguidos pela interrupção desse evento. Isso demonstra similaridade entre a apresentação do estímulo aversivo e a privação, porque esses dois eventos evocam comportamentos e alteram o valor das conseqüências desses comportamentos. 
Michael $(1982,1983)$ sistematizou a descrição dos eventos que Skinner (1953/1993) analisou como privação e saciação, e optou pela expressão operação estabelecedora, que foi sugerida inicialmente por Keller e Schoenfeld (1950/1973) para se referir a esses eventos. Michael definiu operações estabelecedoras como sendo as mudanças ambientais que exercem as funções de: (1) alterar a efetividade de um objeto ou evento como reforçador ou como punidor e (2) alterar, momentaneamente, a freqüência do comportamento que foi seguido por esse reforço ou estímulo punitivo. A primeira é uma função alteradora de repertório que se refere ao fato de as operações ambientais poderem alterar a probabilidade do comportamento, alterando a efetividade da conseqüência. Esse efeito é observado quando as condições apropriadas para emitir esse comportamento estiverem novamente presentes, ou seja, em uma situação futura. A segunda é a função evocativa, que consiste em um aumento imediato e momentâneo de determinados comportamentos, e não de outros. De acordo com Michael (1993), as operações estabelecedoras afetam também a efetividade evocativa dos estímulos discriminativos correlacionados com um reforçador, e aumentam a freqüência de comportamentos que foram seguidos por reforçadores condicionais. Assim, ao se afirmar que a efetividade de um evento ambiental foi modificada, não se quer dizer que as propriedades físicas dos estímulos mudaram, mas que o indivíduo passa a interagir com determinado evento ambiental que, anteriormente, não afetava seu comportamento.

Como exemplo das funções especificadas na definição de Michael, consideremos a situação em que um indivíduo chega a um quarto de hotel e a temperatura desse quarto está desconfortavelmente alta. A temperatura elevada estabelece a sua redução como um reforçador e evoca comportamentos que, no passado, produziram como conseqüência a redução da temperatura ambiental. Essa operação estabelecedora propicia, portanto, condições para a emissão de comportamentos como o de ligar o aparelho de ar condicionado. Freqüentemente, em quartos de hotéis, os interruptores da TV e do ar condicionado estão na cabeceira da cama, lado a lado. Assim, a temperatura elevada evoca a cadeia comportamental de dirigir-se até à cabeceira da cama e acionar o interruptor do aparelho de ar condicionado. A conseqüência é a redução na temperatura ambiental, o que reforça essa cadeia comportamental. Quando os interruptores de cada um dos aparelhos não são facilmente discrimináveis pelo hóspede, ele terá que emitir outros comportamentos que permitam que ele faça essa discriminação. Ele poderá, por exemplo, acionar um dos interruptores, testando o efeito que produz. Se a TV ligar, e não o aparelho de ar condicionado, ele tentará o outro interruptor. Além disso, após essa discriminação ter sido feita, o interruptor do aparelho de ar condicionado passa a ter a função de $S^{\mathrm{D}}$ e, também, a função de reforço condicional. O interruptor torna-se um reforçador para a resposta de se dirigir até a cabeceira da cama, dentro da cadeia comportamental que teve início na hora em que o hóspede entrou no quarto. Assim, a temperatura ambiental elevada é a operação estabelecedora que: 1) aumentou o valor reforçador da redução na temperatura; 2) evocou comportamento que no passado produziu redução de temperatura, como ligar o aparelho de ar condicionado, abrir a janela, entre outros; 3) aumentou a eficácia do interruptor do aparelho como um $S^{D}$ e 4) aumentou a efetividade desse interruptor como um reforçador condicional 
para as respostas que possibilitam acionar o interruptor, como a de dirigir-se até à cabeceira da cama.

Os exemplos clássicos de operações estabelecedoras apresentados por Michael (1982, 1983), que foram aqueles analisados por Skinner (1953/1993), são a privação e a saciação. Michael destacou que essas duas operações exercem efeitos complementares. A privação de alimento, por exemplo, altera o repertório de um organismo por aumentar o valor reforçador do alimento, e evoca os comportamentos que foram reforçados pelo alimento. A saciação, por outro lado, diminui a efetividade do alimento como um reforçador, e suprime os comportamentos que são mantidos por esse tipo de conseqüência. Esses exemplos evidenciam o caráter bidirecional das operações estabelecedoras, cuja definição deve incluir, portanto, o sentido de estabelecer e o de abolir comportamentos (abolishing operations, em inglês).

Michael (1983) especificou diversas outras operações estabelecedoras, além da privação e da saciação, como, por exemplo, a mudança de temperatura ambiental e corporal, as alterações hormonais, a ingestão de substâncias salgadas e as estimulações aversivas, que serão objeto da presente análise devido à relevância para o contexto odontopediátrico. Além disso, ele classificou esses eventos em operações estabelecedoras incondicionais e condicionais. As operações estabelecedoras incondicionais são aquelas que têm essa função por origem filogenética, ou seja, a efetividade de um evento reforçador ou punidor e as propriedades evocativas desses eventos não são aprendidas, mas estabelecidas por herança genética. São exemplos desse tipo de operação estabelecedora a privação e a saciação de alimento, de água, de atividade e do sono, as mudanças de temperatura ambiental ou corporal, as variáveis relacionadas à estimulação sexual e os eventos que produzem dano ao organismo, designados genericamente estímulos aversivos.

As operações estabelecedoras condicionais são aquelas que têm essa função devido à história de aprendizagem de cada indivíduo, que envolve o emparelhamento de eventos neutros com operações estabelecedoras incondicionais. Portanto, esse tipo de operação estabelecedora varia de indivíduo para indivíduo, dependendo da história que cada indivíduo vivenciou. Um exemplo citado por Haydu (2004) é a situação em que se tem um compromisso para almoçar, com hora marcada. Esse compromisso estabelece a informação de horário como um reforço. Além disso, esse compromisso aumenta a probabilidade de vários comportamentos, como olhar para o pulso, quando se usa relógio, olhar o visor no celular ou olhar para as paredes para ver se há um relógio pendurado nelas ou, ainda, perguntar "Que horas são?" para alguém que está por perto usando um relógio.

Os paradigmas da fuga e da esquiva servem, também, para exemplificar apropriadamente como são estabelecidas, ontogeneticamente, as funções de operação estabelecedora. $\mathrm{Na}$ fuga, o término de um estímulo aversivo incondicional reforça negativamente o comportamento que produziu esse efeito. Esse comportamento é evocado pela apresentação do estímulo aversivo, e é aprendido ao longo das experiências do indivíduo (Michael, 1983). Uma tempestade, por exemplo, é uma operação estabelecedora que faz com que um abrigo seja um reforçador e evoca comportamentos que, no passado, produziram a possibilidade de se abrigar da chuva, ou seja, o estímulo aversivo 
incondicional tem a função de operação estabelecedora incondicional, porque estabelece o abrigo como um reforço e aumenta a probabilidade de ocorrência de comportamentos como o de procurar abrigo. Estímulos neutros emparelhados de forma sistemática com estímulos aversivos incondicionais podem adquirir a função aversiva e, dessa forma, exercerem a função de operações estabelecedoras condicionais, como acontece no paradigma da esquiva. Chuva forte, por exemplo, é uma operação estabelecedora incondicional, que freqüentemente é precedida por trovoadas, que são ouvidas antes de a tempestade chegar. Abrigar-se e levar o guarda-chuva são comportamentos estabelecidos pelas trovoadas, que podem, portanto, ser denominadas operações estabelecedoras condicionais.

De acordo com Michael (1982, 1983, 1993), é muito comum que analistas do comportamento identifiquem as operações estabelecedoras presentes no paradigma da fuga e da esquiva como estímulos discriminativos $\left(\mathrm{S}^{\mathrm{D}}\right)$. Segundo ele, os estímulos discriminativos estão relacionados à disponibilidade diferencial do evento reforçador diante de certos comportamentos, isto é, uma conseqüência é apresentada após um determinado comportamento na presença de um dado estímulo $\left(\mathrm{S}^{\mathrm{D}}\right)$, e não é apresentada ou ocorre com freqüência menor na presença de outro estímulo $\left(\mathrm{S}^{\Delta}\right)$. Ao se considerar as operações estabelecedoras, a conseqüência continua sendo um reforçador efetivo, mesmo na ausência do $\mathrm{S}^{\mathrm{D}}$, e a efetividade da operação estabelecedora não depende dessa história de reforço diferencial. O reforço diferencial não está presente quando, por exemplo, um evento aversivo estabelece ocasião para uma resposta de fuga, pois não há extinção para essa resposta na presença de outro estímulo, o $S^{\Delta}$. Não há sentido para a ocorrência de um comportamento de fuga ou de esquiva de um estímulo aversivo ausente, pois a conseqüência não tem nenhum valor reforçador.

\section{Reforço negativo e operações estabelecedoras no contexto odontopediátrico}

Os efeitos de operações estabelecedoras condicionais e incondicionais podem ser observados com detalhes, no contexto da odontopediatria. Para isso, deve-se considerar, a princípio, que a própria posição da criança na cadeira odontológica e o fato de a criança ter que ficar imóvel com a boca aberta por períodos prolongados são condições com alto grau de aversividade, principalmente para crianças. Essas condições evocam comportamentos de movimentar-se e tentativas de livrar-se da imobilidade, que são considerados comportamentos de nãocolaboração pelos dentistas, pois interferem na realização do procedimento odontológico.

Os procedimentos odontológicos e os eventos desse contexto podem, ainda, exercer função de operações estabelecedoras condicionais, conforme demonstram os dados da pesquisa de Rolim, Moraes, César e Costa Júnior (2004). Esses pesquisadores estudaram o comportamento de uma criança de quatro anos, com história de não-colaboração em uma seqüência de atendimentos odontológicos. $\mathrm{Na}$ primeira sessão de procedimentos preventivos (exame clínico, escovação, aplicação tópica de flúor, etc.), houve colaboração por parte da criança. Na segunda sessão, a criança chorou logo que o dentista iniciou a anestesia tópica, que não pôde ser finalizada. Na terceira sessão, a criança permitiu a aplicação tópica do anestésico, mas, no início da anestesia 
injetável, ela chorou, movimentou o corpo e levantou-se da cadeira, produzindo o encerramento da intervenção. Nas duas sessões seguintes, a criança apresentou altos índices de comportamentos não-colaborativos (choro, movimentos corporais, tentativas de sair da cadeira) e não possibilitou a realização de nenhum dos procedimentos. Na sexta sessão, o dentista apelou para a contenção física, a fim de poder efetuar o tratamento odontológico. Essa seqüência mostra que a situação não era aversiva, mas passou a ser, e que ela culminou com a aplicação dessa técnica que tem alta propriedade aversiva incondicional. A contenção física usada nas intervenções odontopediátricas é feita com o uso de abridores de boca ou por meio do chamado "pacote pediátrico", que consiste em embrulhar a criança com tecidos ou cobertores, imobilizando-a completamente. A imobilização pode, ainda, ser feita pelos pais ou por assistentes, que seguram os membros da criança enquanto o dentista faz o tratamento.

Os estímulos que provocam desconforto, como a imobilização, e os que são dolorosos estabelecem seu término como reforçador e evocam comportamentos como empurrar, movimentos do corpo e da cabeça, e o choro. Alguns desses comportamentos são inicialmente respostas reflexas eliciadas por aqueles estímulos, mas, ao produzirem a interrupção do procedimento odontológico, são reforçados negativamente, adquirindo a função operante e caracterizando-se como respostas de fuga. Os eventos aversivos que evocam esses comportamentos de fuga adquirem então a função de operações estabelecedoras, que estabelecem o seu término como reforço.

Além disso, os estímulos dolorosos são, normalmente, precedidos por estímulos que inicialmente são neutros, como, por exemplo, a sensação do esfregar o algodão ao fazer a anestesia tópica, o odor de materiais odontológicos, o som do sugador de saliva, a presença do dentista. Após o emparelhamento de um ou mais desses estímulos neutros com o estímulo doloroso, como a injeção, o estímulo neutro adquire a função de estabelecer o seu término como um reforçador negativo e passará a evocar respostas de esquiva. $\mathrm{O}$ estímulo neutro passa, então, a ter a função de operação estabelecedora condicional.

\section{Estudos que avaliaram o uso de técnicas de intervenção em odontopediatria}

Possobon, Caetano e Moraes (1998) estudaram o efeito da aplicação de um procedimento de intervenção com quatro crianças de dois a três anos de idade que apresentavam comportamento não-colaborativo, submetidas a tratamentos odontológicos cirúrgicos que duraram de seis a nove sessões. A intervenção incluiu o uso de estratégias ("conte-mostrefaça", distração, familiarização, atividade lúdica e reforço positivo) pelo dentista e o acompanhamento de uma psicóloga, que observava os atendimentos e planejava com o dentista o manejo comportamental em cada sessão. O "conte-mostre-faça" é uma técnica que consiste em explicar para o paciente o procedimento odontológico em três passos: primeiro o dentista diz o que será feito, depois ele faz uma demonstração visual e tátil e, por último, ele realiza o tratamento. Os resultados mostram que houve um aumento gradual da colaboração das crianças, com diminuição da resistência, apesar de o choro permanecer presente em quase todas as consultas. Os autores destacaram que as brincadeiras tiveram efeito de reforço positivo para o comportamento de colaborar, e observaram que, a partir da segunda ou terceira sessões, 
o uso de brocas de alta e de baixa rotação evocava comportamentos não-colaborativos. Apesar de terem sido usadas estratégias de familiarização com a criança, o ruído das brocas provocava choro e inquietação mesmo antes de o instrumento ser posicionado na boca da criança, o que indica que o ruído alto do aparelho não perdeu a função aversiva e continuou evocando comportamentos de fuga, que eram reforçados negativamente, com a interrupção do tratamento.

Os prêmios dados para as crianças nem sempre exercem função de reforços positivos, conforme foi demonstrado por Possobon, Moraes, Costa Júnior e Ambrosano (2003), que desenvolveram um estudo com seis crianças de quatro a cinco anos de idade, todas elas com uma história de não-colaboração, que impediu ou interrompeu a realização de tratamento odontológico anterior. Essas crianças foram submetidas a cinco sessões, nas quais o dentista estabelecia para as crianças duas regras: elas poderiam brincar após a consulta e levar um brinde quando cooperassem. Caso não colaborassem, a sessão seria encerrada sem direito ao brinde ou aos brinquedos. Os resultados mostram que houve predomínio de comportamentos não-colaborativos nas cinco consultas, e que os procedimentos odontológicos não puderam ser realizados pelo dentista. Os pesquisadores concluíram que os prêmios pela colaboração não tiveram efeito reforçador, pois esses comportamentos não aumentaram quando os prêmios foram oferecidos.

Para as crianças com alta freqüência de comportamento não-colaborativo, as instruções, os elogios e os brindes contingentes ao comportamento colaborativo podem não ser sempre apropriados para estabelecer ou manter esse tipo de comportamento, porque os comportamentos concorrentes se caracterizam como respostas de fuga e de esquiva. Provavelmente, para crianças com história de não-colaboração e que foram submetidas a procedimentos invasivos, o valor do reforçador negativo (interrupção ou adiamento do procedimento odontológico) é muito mais forte do que o valor reforçador positivo de elogios e dos demais estímulos (brindes e brincadeiras) apresentados de forma contingente ao comportamento de colaboração, conforme sugerem os dados dessas e de outras pesquisas, como as de Stark et al. (1989) e a de Fioravante, Soares, Silveira e Zakir (2007).

O efeito da estimulação aversiva como operação estabelecedora e a independência desse efeito em relação às outras variáveis manipuladas pelo dentista, como os brinquedos, foram demonstrados no estudo de Stark et al., com os resultados de um procedimento no qual foi testada a eficiência da distração combinada ao reforçamento positivo. Crianças que apresentavam comportamentos de não colaborar ouviam uma história por meio de fones auditivos, a qual era simultaneamente ilustrada por painéis durante os atendimentos odontológicos. No final de cada sessão, elas respondiam algumas perguntas sobre a história e, caso acertassem a maioria delas, tinham direito a um brinquedo e a um tempo para jogar videogame. A intervenção surtiu efeito apenas inicialmente. A diminuição de comportamentos nãocolaborativos não se manteve para duas das quatro crianças, quando elas tiveram que ser submetidas a mais de uma sessão de intervenção. O comportamento de nãocolaboração aumentou nas sessões sucessivas, mas as crianças continuaram respondendo corretamente as perguntas sobre a história e, portanto, recebendo os prêmios. De acordo com os autores, possivelmente, o 
dentista parava ou atrasava o procedimento odontológico de forma contingente aos comportamentos não-colaborativos, o que os reforçava; com isso, as crianças aprenderam que podiam emitir respostas de fuga e esquiva ao tratamento e, ao mesmo tempo, responder um número suficiente de perguntas para ganhar o brinde. As interrupções temporárias dos procedimentos efetuadas pelo dentista competiram com a distração e o reforçamento positivo, que não foram suficientes para estabelecer e manter o comportamento de colaboração.

Fioravante et al. (2007) registraram os comportamentos de quatro crianças, duas colaboradoras e duas que não colaboravam, e analisaram as contingências que mantinham esses comportamentos, principalmente na relação com os comportamentos positivos e negativos das dentistas que atenderam essas crianças. Como condutas positivas, foram consideradas as respostas de descrever, fantasiar, elogiar, distrair, fazer perguntas e oferecer conforto físico, enquanto as condutas negativas incluíram criticar, restringir fisicamente, dar ordens e deixar a criança sozinha. Os resultados demonstraram que a colaboração da criança esteve relacionada a condutas positivas, enquanto comportamentos não-colaborativos estavam relacionados a condutas negativas das dentistas.

Os resultados dos estudos citados nesta seção sugerem, portanto, que comportamentos de se movimentar muito, de chorar, de reclamar e de empurrar fazem com que os dentistas interrompam o procedimento odontológico, o que aumenta a probabilidade de ocorrência desses comportamentos no futuro. A não-colaboração caracteriza-se em comportamentos de fuga ou de esquiva do estímulo doloroso ou do estímulo que foi emparelhado com estímulos dessa natureza, isto é, há uma operação estabelecedora, que é o estímulo aversivo que estabelece o seu término como reforço (reforço negativo). Além disso, é possível que os brindes ou brincadeiras tenham poder reforçador enfraquecido para o comportamento colaborativo por serem apresentados com atraso, ou seja, somente após o final da consulta. Existe, ainda, a possibilidade de não terem valor reforçador nenhum, porque as crianças que freqüentam ambientes odontológicos, de forma geral, não têm privação de brinquedos. A maioria das crianças tem brinquedos disponíveis o tempo todo em suas casas, e as brincadeiras são parte das atividades rotineiras em escolas de educação infantil e ensino fundamental.

Para que a análise funcional apresentada nesta seção fique clara, é importante destacar que um mesmo evento pode exercer diversas funções. Certos estímulos, como os dolorosos, podem eliciar reações reflexas incondicionais, incluindo as que são identificadas como medo, e tem, nesse caso, a função de estímulo aversivo incondicional. Outros estímulos, que inicialmente são neutros, como, por exemplo, o som do sugador ou os odores de materiais odontológicos, após serem emparelhados com os estímulos eliciadores incondicionais, como os que provocam dor, passam a eliciar comportamentos reflexos condicionais e também podem passar a exercer a função de operação estabelecedora quando o seu término tem função de reforço.

\section{Procedimentos de controle da fuga e da esquiva}

Com o objetivo de manipular de forma direta a contingência de reforço negativo em contexto odontopediátrico, pesquisadores como Allen e Stokes (1987) e Allen, Loiben, Allen e Stanley (1992) testaram experimentalmente 
1 Sugere-se reconsiderar o uso da expressão "fuga contingente". De acordo com os princípios da análise do comportamento, a fuga é um comportamento que elimina uma estimulação aversiva, enquanto a operação (procedimento) que elimina ou evita o estímulo aversivo é denominada reforço negativo. Além disso, quando o procedimento odontológico é interrompido de forma contingente ao comportamento colaborativo da criança, esse comportamento pode ser de fuga ou de esquiva. Assim, sugere-se o uso da expressão "interrupção contigente".

2 A expressão "fuga não-contingente" também não é adequada, no entanto, pesquisadores dessa área de estudos, apesar de reconhecerem essa falta de precisão, continuam utilizando essas expressões, porque considerarem que elas estão bastante difundidas, conforme sugeriram Carr e Leblanc (2006). estratégias em que a estimulação aversiva, ou seja, o procedimento odontológico, era interrompido por alguns segundos de forma contingente ao comportamento de colaborar com o dentista, procedimento denominado por esses autores de "fuga contingente" 1 . Esse procedimento produziu a redução dos comportamentos não-colaborativos de todos os participantes. Tais resultados podem ser explicados pela quebra da contingência anteriormente estabelecida entre comportamentos de não-colaboração e a interrupção do procedimento odontológico. As crianças aprenderam que, se ficassem paradas e quietas, produziriam a interrupção momentânea do tratamento, ou seja, o reforçador negativo era contingente aos comportamentos colaborativos.

Apesar de a estratégia de interrupções contingentes ser teoricamente fundamentada nos princípios do reforço, deve-se considerar a viabilidade de sua aplicação. Allen e Stokes (1987) reconheceram que, se a aplicação do procedimento for feita por um psicólogo, como no estudo por eles desenvolvido, há custos para o dentista, tanto em tempo de consulta quanto financeiro, o que torna o uso da estratégia pouco viável. Para controlar esse problema, Allen et al. (1992) ensinaram a técnica ao próprio dentista, mas ele apresentou dificuldades em aplicá-la e não manteve o uso após a pesquisa.

Na busca de contornar essas dificuldades de aplicação, O'Callaghan, Allen e Powell (2006) testaram interrupções não-contingentes ao comportamento infantil, procedimento denominado "fuga não-contingente" ${ }^{2}$. Em vez de pausas no procedimento odontológico de acordo com a colaboração da criança, os dentistas realizaram interrupções controladas por um timer, em intervalos de tempo fixos, independentemente do que a criança estivesse fazendo. Nesse caso, também ocorreu um processo de extinção, porque houve o rompimento da relação entre o comportamento e a conseqüência, ou seja, a contingência entre o comportamento e o reforço foi desfeita: choros ou movimentos do corpo não mais interrompiam a ação do dentista; a interrupção ocorria independentemente dos comportamentos. Com essa intervenção, os pesquisadores observaram diminuição dos comportamentos não-colaborativos.

Uma tentativa de replicação do procedimento utilizado por O'Callaghan et al. (2006), em que a técnica de interrupção não-contingente foi usada, apresentou dificuldades que sugeriram que a técnica apresenta sérias restrições. Brandenburg e Marinho (2007) realizaram um estudo-piloto com três crianças com idades entre dois e cinco anos, avaliadas como não-colaborativas na sessão em que foi estabelecida a linha de base. Para a intervenção, duas dentistas foram instruídas a procederem normalmente e a interromperem o procedimento odontológico apenas diante da emissão do som de uma campainha, que soava em intervalos fixos. Cada criança foi filmada durante três ou quatro sessões de tratamento cirúrgico, e os dados da filmagem indicaram que não houve diminuição da não-colaboração. O principal problema observado foi que as dentistas nem sempre interromperam o procedimento no momento das indicações do som. Elas relataram que as pausas prejudicavam a eficiência do trabalho odontológico e que dificultavam ainda mais o controle do comportamento infantil, que piorava depois das pausas. Brandenburg e Marinho, a partir de conversas informais com outros dentistas, além dos que participaram do estudo-piloto por elas desenvolvido, concluíram que a estratégia de interromper o tratamento de forma não-contingente em 
intervalos regulares não é viável, porque o dentista não pode interromper o que está fazendo a qualquer momento. Ao fazer uma restauração, por exemplo, o dentista não pode deixar de enxaguar o dente após a colocação do ácido, pois o tempo de exposição a essa substância tem que ser rigorosamente controlado; após aplicar a resina, o dentista não pode permitir que a criança feche a boca, pois a saliva impede que a resina endureça, e assim por diante. As interrupções podem ser feitas apenas em momentos particulares, nos intervalos entre procedimentos específicos.

\section{Possíveis soluções e considerações finais}

Os questionamentos feitos por Brandenburg e Marinho (2007), por Allen e Stokes (1987) e por Allen et al. (1992) alertam para as dificuldades do uso das estratégias de interrupção contingente e interrupção não-contingente durante o procedimento odontológico. No entanto, as análises feitas por esses autores, bem como as de outros estudos da área, permitem sugerir que os comportamentos não-colaborativos são comportamentos de fuga e de esquiva estabelecidos por eventos que têm funções de operações estabelecedoras incondicionais e condicionais. Considerando-se que as funções de operações estabelecedoras condicionais são dependentes da história de interação de cada criança com os eventos ocorridos nas experiências odontológicas anteriores, devese destacar o quão importante é programar contingências que tornem a situação o menos aversiva possível.

Isso pode ser feito, conforme demonstraram os resultados dos estudos desenvolvidos por Stokes e Kennedy (1980) e por Allard e Stokes (1987), por meio de procedimentos que combinaram a técnica de observação de outras crianças em tratamento com a de reforço positivo do comportamento de colaborar com o dentista. Em ambos os estudos, foram atendidas crianças de seis e sete anos com história de não-colaboração, que foram submetidas a procedimentos de restauração. As crianças observaram o atendimento de uma criança colaborativa antes de sua consulta e receberam brindes quando colaboravam com o dentista. Os resultados mostraram que houve grande redução dos comportamentos não-colaborativos.

Outro exemplo de planejamento de contingência é a pesquisa de Ingersoll, Nash, Blount e Gamber (1984). Trinta e cinco crianças, com idade entre três e nove anos, foram aleatoriamente distribuídas em três grupos depois do primeiro atendimento do tratamento de restauração (linha de base). Os grupos eram os seguintes: 1) grupo controle, com tratamento odontológico sem nenhuma intervenção adicional; 2) grupo em que um desenho animado estava disponível por todo o tratamento odontológico; 3) grupo em que a exibição do desenho animado durante a consulta era contingente ao comportamento da criança, a televisão era acionada somente no momento em que a criança estava colaborando. Os autores denominaram essa intervenção do terceiro grupo distração contingente, pois o desenho animado era apresentado simultaneamente ao tratamento odontológico, mas somente diante da colaboração da criança. Os comportamentos de não-colaboração foram registrados por meio de observação direta. Os resultados indicaram diferença estatística entre o primeiro e o terceiro grupos: as crianças submetidas à distração contingente apresentaram redução de comportamentos não-colaborativos. 
A técnica de distração não se mostrou eficiente no estudo de Stark et al. (1989), mas foi eficaz ao ter sido usada de forma contingente ao comportamento de colaboração da criança por Ingersoll et al. (1984). Certamente, há diferenças de população e de método entre as pesquisas. Ingersoll et al. não selecionaram crianças com alto índice de não-colaboração, como foi feito por Stark et al. (1989), e utilizaram análises estatísticas. No entanto, estabelecer uma contingência entre a distração visual e os comportamentos colaborativos pode ser uma alternativa interessante. Ao estabelecer a dependência entre os dois eventos, verifica-se que o comportamento colaborativo passa a ser reforçado positivamente de forma imediata pelo desenho animado, aumentando a efetividade da distração.

Kuhn e Allen (1994) sugerem que mais pesquisas deveriam ser realizadas sobre a distração contingente, com crianças mais novas e menos colaboradoras. Esses autores, em um artigo de revisão sobre diferentes técnicas de manejo citadas na bibliografia da área, consideraram como alternativas promissoras as técnicas de distração contingente à colaboração (Ingersoll et al., 1984), a de interrupção contingente (Allen et al., 1992) e a de observação do tratamento de outra criança (Stokes \& Kennedy, 1980). Kuhn e Allen destacaram aspectos positivos em relação a essas técnicas, que demonstram eficácia científica, são de fácil aplicação e não são invasivas. No entanto, são técnicas ainda não muito disseminadas entre os dentistas (Allen, Stanley, \& McPherson, 1990) e ainda não constam no Guia da AAPD.

Kuhn e Allen (1994) ressaltam que analistas do comportamento com experiência em lidar com crianças não-colaborativas podem contribuir de forma significativa com a odontopediatria. A análise funcional do comportamento possibilita compreender porque é tão freqüente a emissão de comportamentos não-colaborativos por parte das crianças, com predomínio das respostas de fuga e esquiva, que passam a ser tão persistentes que podem se estender até quando essas crianças se tornam adultos. $\mathrm{O}$ conceito de operação estabelecedora permite compreender porque a fuga e a esquiva persistem, mesmo em algumas situações em que o comportamento de colaborar é reforçado positivamente com brinquedos ou com outros tipos de brindes. A noção de condicionamento de funções respondentes e operantes permite compreender porque os eventos neutros do ambiente odontológico adquirem funções de estímulo eliciador condicional, estímulo punitivo condicional e de operação estabelecedora condicional. Isso, por sua vez, permite que se entenda porque as crianças divergem no comportamento diante de um mesmo profissional quando este usa uma mesma técnica de manejo do comportamento, conforme foi demonstrado por Moraes, Sanchez, Possobon e Costa Junior (2004). Cada paciente passa por uma história específica de emparelhamentos, ficando seus comportamentos sob o controle de diferentes variáveis, ou seja, a história de contingências aversivas e de emparelhamentos de estímulos neutros com os estímulos aversivos com função de operação estabelecedora aumenta o número de eventos do ambiente que controlam respostas de fuga e de esquiva, conforme demonstraram os resultados da pesquisa desenvolvida por Fioravante et al. (2007).

Conclui-se que as pesquisas baseadas no conceito de operações estabelecedoras e 
no reforço dos comportamentos de fuga

e esquiva trazem esclarecimentos sobre o manejo do comportamento infantil em odontopediatria e chamam a atenção para a necessidade de técnicas que diminuam a aversividade desse contexto, portanto, existem alternativas para que tanto a criança quanto o odontopediatra sejam beneficiados, sem que se tenha que apelar para a contenção física.

Olivia Justen Brandenburg*

Mestre em Análise do Comportamento pela Universidade Estadual de Londrina.

Docente do Curso de Psicologia da Faculdade Sant'Ana - PG/PR e da Faculdade de Administração, Ciências, Educação e Letras (FACEL) - Ctba/PR.

\section{Verônica Bender Haydu}

Doutora pela Universidade de São Paulo, na área de Psicologia Experimental.

Docente do Departamento de Psicologia Geral e Análise do Comportamento da Universidade Estadual de Londrina (UEL) - Londrina/PR.

E-mail: veronicahaydu@gmail.com

* Endereço para envio de correspondência:

Cecília Mikosz, 219, cs 07. Curitiba - PR - Brasi, CEP 82130-330

E-mail: oliviajb@onda.com.br 


\section{Referências}

Allard, G., \& Stokes, T. F. (1980). Continuous observation: A detailed record of children's behavior during dental treatment. Journal of Dentistry for Children, 47, 246-250.

Allen, K. D., \& Stokes. T. F. (1987). Use of escape and reward in the management of young children during dental treatment. Journal of Applied Behavior Analysis, 20(4), 381-390.

Allen, K. D., Loiben, T., Allen, S. J., \& Stanley, R. T. (1992). Dentist: Implemented contingent escape for management of disruptive child behavior. Journal of Applied Behavior Analysis, 25, 629-636.

Allen, K. D., Stanley, R. T., \& McPherson, K. E. (1990). Evaluation of behavior management technology dissemination in pediatric dentistry. Pediatric Dentistry, 12, 79-82.

American Academy of Pediatric Dentistry. (2005-2006). Guideline on behavior guidance for the pediatric dental patient (Reference Manual). Chicago: Author.

Brandenburg, O. J., \& Marinho, M. L. (2007). Intervenção para comportamento não-colaborativo em atendimento odontopediátrico - estudo piloto. In XXXVII Reunião Anual de Psicologia, Florianópolis.

Carr, J. E., \& LeBlanc, L. A. (2006). Noncontingent reinforcement (NCR) as antecedent behavior support. In J. K. Luiselli (Ed.), Antecedent intervention: Recent developments in community focused behavior support (pp. 147-164). Baltimore, MD: Brookes.

Keller, F. S., \& Schoenfeld, W. N. (1973). Princípios de psicologia. São Paulo: EPU. (Trabalho original publicado em 1950)

Kuhn, B. R., \& Allen, K. D. (1994). Expanding child behavior management technology in pediatric dentistry: A behavioral science perspective. Pediatric Dentistry, 16, 13-17.

Fioravante, D. P., Soares, M. R. Z., Silveira, J. M., \& Zakir. N. S. (2007). Análise funcional da interação profissional-paciente em odontopediatria. Estudos de Psicologia, 24(2), 267-277.

Haydu, V. B. (2004). O que é operação estabelecedora? In C. E. Costa, J. C. Luzia \& H. H. N. Sant'Anna (Eds.), Primeiros passos em análise do comportamento e cognição (Vol. 2, pp. 59-66). Santo André, SP: Esetec.

Ingersoll, B. D., Nash, D. A., Blount, R. L., \& Gamber, C. (1984). Distraction and contingent reinforcement with pediatric dental patients. Journal of Dentistry for Children, 51, 203-207.
Michael, J. (1982). Distinguishing between the discriminative and motivational functions of stimuli. Journal of the Experimental Analysis of Behavior, 37, 149-155.

Michael, J. (1983). Evocative and repertoire-altering effects of an environmental event. Analysis of Verbal Behavior, 6, 3-9.

Michael, J. (1993). Establishing operations. The Behavior Analyst, $16,191-206$

Moraes, A. B. A., Sanchez, K. A. S., Possobon, R. F., \& Costa Júnior, A. L. (2004). Psicologia e odontopediatria: a contribuição da análise funcional do comportamento. Psicologia: Reflexão e Crítica, 17(1), 75-82.

O'Callaghan, P. M., Allen, K. D., \& Powell, S. (2006). The efficacy of noncontingent escape for decreasing children's disruptive behavior during restorative dental treatment. Journal of Applied Behavior Analysis, 39(2), 161-171

Possobon, R. F., Caetano, M. E. S., \& Moraes, A. B. A. (1998). Odontologia para crianças não- colaboradoras: relato de casos. Revista Brasileira de Odontologia, 55(2), 80-83.

Possobon, R. F., Moraes, A. B. A., Costa Júnior, A. L., \& Ambrosano, G. M. B. (2003). O comportamento de crianças durante atendimento odontológico. Psicologia: Teoria e Pesquisa, 19(1), 59-64

Rolim, G. S., Moraes, A. B. A, César, J., \& Costa Júnior, A. L. (2004). Análise do comportamento do odontólogo no contexto de atendimento infantil. Estudos de Psicologia, 9(3), 533-541.

Skinner, B. F. (1993). Ciência e comportamento humano. São Paulo: Martins Fontes. (Trabalho original publicado em 1953).

Stark, L. J., Allen, K. D., Hurst, M., Nash, D. A., Rigney, B., \& Stokes, T. F. (1989). Distraction: Its utilization and efficacy with children undergoing dental treatment. Journal of Applied Behavior Analysis, 22, 297-307.

Stokes, T. F., \& Kennedy, S. H. (1980). Reducing child uncooperative behavior during dental treatment through modeling and reinforcement. Journal of Applied Behavior Analysis, 13, 41-49. 